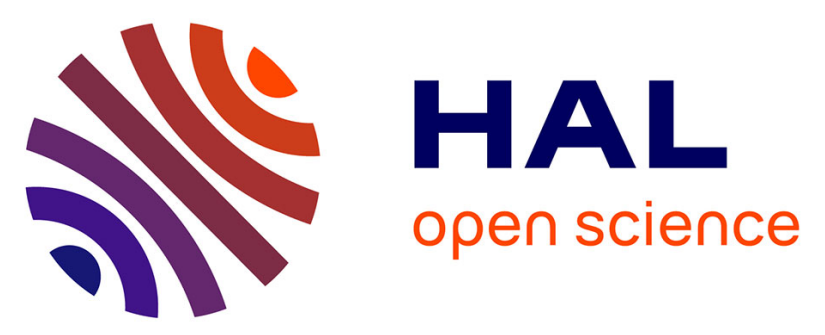

\title{
A NEW APPROACH FOR THE MATHEMATICAL ALIGNMENT MACHINE TOOL-PATHS ON A FIVE-AXIS MACHINE AND ITS EFFECT ON SURFACE ROUGHNESS
}

Salim Boukebbab, Julien Chaves-Jacob, Jean-Marc Linares, Noureddine

Azzam

\section{To cite this version:}

Salim Boukebbab, Julien Chaves-Jacob, Jean-Marc Linares, Noureddine Azzam. A NEW APPROACH FOR THE MATHEMATICAL ALIGNMENT MACHINE TOOL-PATHS ON A FIVEAXIS MACHINE AND ITS EFFECT ON SURFACE ROUGHNESS. ADVANCED MATHEMATICAL AND COMPUTATIONAL TOOLS IN METROLOGY AND TESTING X, 2015, 978-981-467861-2. hal-01463424

\section{HAL Id: hal-01463424 \\ https://hal-amu.archives-ouvertes.fr/hal-01463424}

Submitted on 9 Feb 2017

HAL is a multi-disciplinary open access archive for the deposit and dissemination of scientific research documents, whether they are published or not. The documents may come from teaching and research institutions in France or abroad, or from public or private research centers.

$$
\text { Copyright }
$$

L'archive ouverte pluridisciplinaire HAL, est destinée au dépôt et à la diffusion de documents scientifiques de niveau recherche, publiés ou non, émanant des établissements d'enseignement et de recherche français ou étrangers, des laboratoires publics ou privés. 


\title{
A NEW APPROACH FOR THE MATHEMATICAL ALIGNMENT MACHINE TOOL-PATHS ON A FIVE-AXIS MACHINE AND ITS EFFECT ON SURFACE ROUGHNESS
}

\author{
SALIM BOUKEBBAB ${ }^{1}$, JULIEN CHAVES-JACOB ${ }^{2}$ \\ ${ }^{1}$ Laboratoire Ingénierie des Transports et Environnent, \\ Faculté des Sciences de la Technologie \\ Université Constantine 1, Campus Universitaire Zarzara, \\ 25000 Constantine, Algérie \\ Tel: $+213(0) 31819066$ \\ E-mail : boukebbab@umc.edu.dz

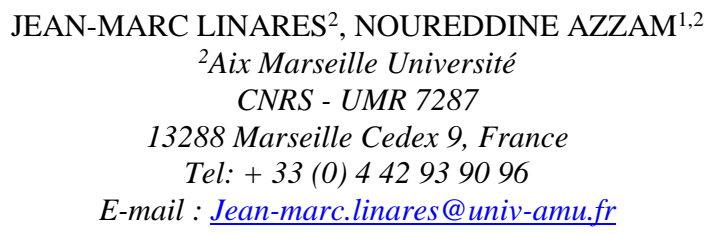

\begin{abstract}
This paper proposes a procedure to adapt the geometry of the toolpath to remove a constant thickness on a five-axis machine. The aim of this work is to contribute to the automation of prosthesis machining, mainly, in the preparation of polishing surface. The proposed method can deform and adapt a toolpath to respect the geometry of the manufactured surface. This method is based on three steps: alignment, deformation and smoothing toolpath. In the alignment step, a mapping is carried out between the measured surface of prostheses and the nominal toolpath using the Iterative Closest Point (ICP) algorithm. The aligned toolpath is deformed in two steps. The first step is the projection of aligned points on the measured surface (defined by STL file). In the second step, these points are offset by a value $\left(a_{p}\right)$ to obtain the required geometry. During the deformation step a meshed surface is used, reducing the smoothness of the deformed toolpath. Experimental tests on industrial prostheses are conducted to validate the effectiveness of this method. During these tests the effects of the smoothing methods on the surface quality of machined parts are presented.
\end{abstract}

\section{Introduction}

The surface quality of surgical implants is one of the most important properties to be controlled in their design and manufacture. The polishing operation represents the final action in the production cycle to improve the quality of implants surfaces. Generally, knee prosthesis is constituted of three parts. Two metal parts are fixed respectively on the femur and one on the tibia. The third 
part is intercalated between the two metallic's and it is made up of a very strong plastic resistant called the polyethylene, which improves the knee slip [1].

To reduce the removed bone volume the knee prostheses thickness is reduced. Thus, this small thickness is caused by deformations due to the foundry process [2]. The geometry has a small influence on the lifespan of the prosthesis, because the intercalated parts in polyethylene will be deformed to compensate geometry errors of the femoral part which is commonly made in cobalt-chromium alloy. On the other hand, the surface discontinuities and the surface quality (roughness and waviness) have a major influence on the lifespan of the prosthesis; this implies that we must have a very accuracy surface quality and to ensure the thickness of the prosthesis to avoid the prosthesis failure. When CNC machines are used to polish these functional surfaces, the polishing force is not controlled because usual $\mathrm{CNC}$ machines drive the position and not the applied force. This effect requires a geometrical adaptation of the machining toolpath at each rough work piece [3]. In manual polishing, the operator uses his eyes to adapt his toolpath.

In the proposed method, a three-dimensional measurement is needed to obtain the rough part geometry made by foundry process. An STL model is generated after this measurement process, it should be noted here that the STL format is obtained by a triangulation of real work piece after acquisition step. The initial tool trajectory is calculated by a CAM (Computer Aided Manufacturing). It is defined on the nominal model given by CAD (Computer-aided design) software, with the respect of toolpath synchronization (figure 1). It makes it possible to avoid the traces on manufactured surface and thus avoid the build of CAD model of each deformed part and to remake a special CNC program [4-5].

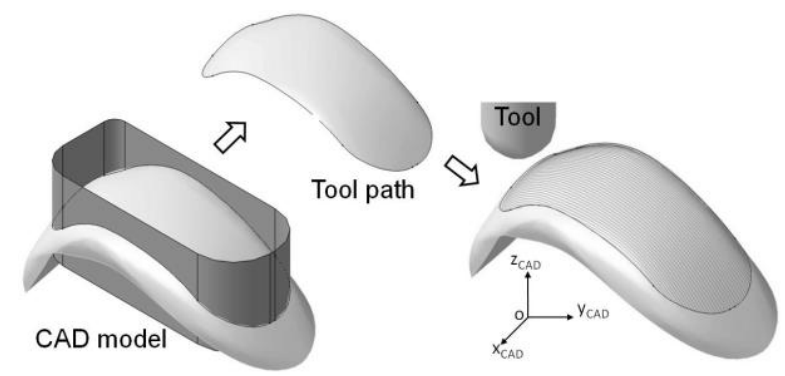

Figure 1: Tool-path generate using CAD model of the knee prosthesis (femoral condyle).

The main objective of this research work is to modify a trajectory of machining calculated on a nominal model to remove a constant thickness over a rough surface of part coming from the foundry. In this paper, the case of femoral 
component of knee prostheses (femoral implant: condyles) is studied. The CNC toolpaths are made only on the upper part of the knee condyle.

\section{Description of the developed procedure}

This study proposes a method to adapt the geometry of the toolpath with the aim to remove a constant thickness. As presented in introduction, this case is present in the machining process of the femoral component of knee prostheses. The figure 2 illustrates the stages of this method. The proposed toolpath deformation method is composed of three stages: the measured surface alignment, toolpath deformation and toolpath smoothing. Each of these three items is studied in relation to the bibliography.

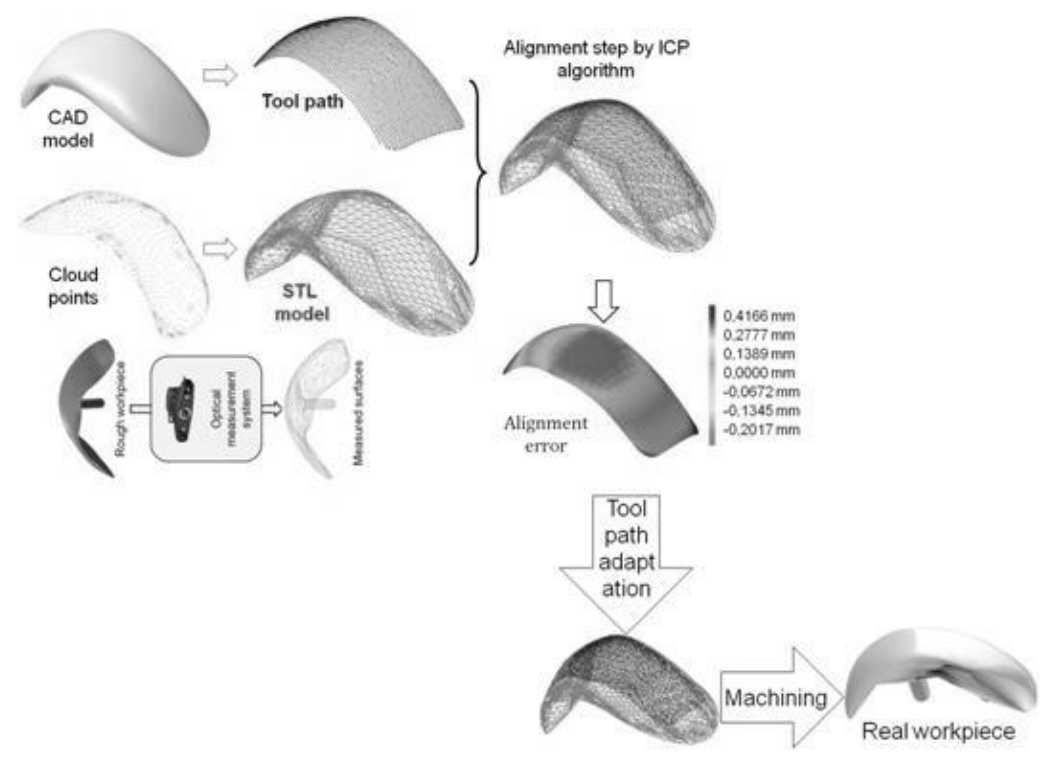

Figure 2: The stage of the method

The deformation of the toolpath is performed in three steps:

a) Aligning the tool path (computed on the nominal model) and the STL model of the rough surface using the ICP algorithm,

b) Deformation of the tool path,

c) Smoothing of the deformed toolpath. 


\section{The alignment process using ICP algorithm}

The alignment process using the ICP algorithm begins by the measurement of rough surface which must be aligned with the nominal toolpath. The ICP algorithm is a well-known method for registering a $3 \mathrm{D}$ set of points to a $3 \mathrm{D}$ model [6]. It will be noted that the successive coordinates of the drive point expressed in the coordinate system of the workpiece give the nominal toolpath. Some CAM software options allow expression of the toolpath of the cutter contact point [3]. Subsequently, these coordinates are noted $P_{C C}\left(x_{i}, y_{i}, z_{i}\right)$ and the tool axis direction, $\boldsymbol{u}$. On the other hand, an STL file defines the measured surface [7]. It is composed of vertices, edges, and triangular facets. Each facet has a normal vector, $\boldsymbol{n}$. It should be noted here that $P^{\prime}{ }_{C C}\left(x_{i}, y_{i}, z_{i}\right)$ is the vertical projection of $P_{C C}\left(x_{i}, y_{i}, z_{i}\right)$ on a triangular facet. A rigid transformation [Tt] consists in the rotation matrix $[\mathbf{R}]$ and the translation vector $\{\mathbf{T}\}$ giving the iterative transformation Eq. 1 .

$$
P^{\prime}{ }_{C C}\left(x_{i}, y_{i}, z_{i}\right)=[\mathrm{R}] \times P_{C C}\left(x_{i}, y_{i}, z_{i}\right)+\{\mathrm{T}\}
$$

The transformation is calculated in the aim to displace the nominal toolpath on the measured surface. The algorithm minimizes the sum of squared residual errors between the set of points and the model, and finds a registration that is locally the best fit using the least-squares method Eq. 2.

$$
f([R],\{T\})=\frac{1}{N_{s}} \sum_{i=1}^{N_{s}}\left\|P_{C C_{i}}^{\prime}-\left[T_{t}\right] \times P_{C C_{i}}\right\|^{2}
$$

\section{Deformed toolpath and offset step}

After alignment phase, the toolpath is deformed in two steps (figure 3). In the first one the projection of the aligned points on the measured surface (STL model) is realised. In the second step, an offset of these points by a value $\left(a_{p}\right)$ is necessary to obtain the required geometry. These steps are detailed below.

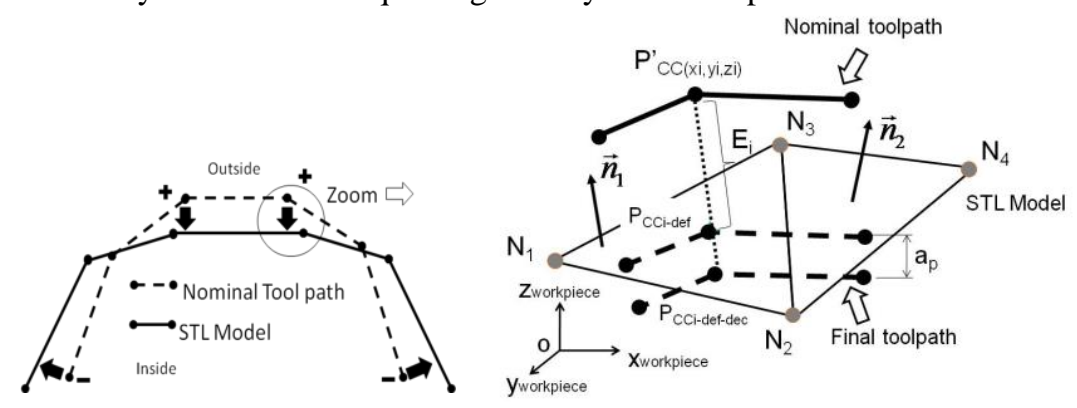

Figure 3: Deformation of the nominal toolpath 


\subsection{Projection aligned points}

Firstly, all the points of the trajectory $P^{\prime}{ }_{C C}\left(x_{i}, y_{i}, z_{i}\right)$ are projected on all facets of the STL model. A test is carried out to verify if the projection is inside the triangle or not. The distance between $P^{\prime}{ }_{C C}(x i, y i, z i)$ and a triangular element of STL model (figure 3) is determinate using the Eq. 3. The triangle vertices are denoted $\mathrm{N}_{1}, \mathrm{~N}_{2}$ and $\mathrm{N}_{3}$. Eq. 4 is used to calculate the point $\mathrm{P}_{\mathrm{CC} \_ \text {def }}(x i, y i$,zi $)$.

$$
\begin{gathered}
\mathrm{E}_{\mathrm{i}}=P_{C C i} N_{l} \cdot n \\
O P_{C C_{-} \text {def }}(x i, y i, z i)=O P^{\prime}{ }_{C C}(x i, y i, z i)+E i \cdot n
\end{gathered}
$$

Where $n$ is the unit vector of the triangular element and $E_{i}$ is the distance between $P^{\prime}{ }_{C C}(x i, y i, z i)$ and $P_{C C \_d e f}(x i, y i, z i)$.

\subsection{Offsetting the toolpath after projection}

The projected toolpath is offset with a quantity $a_{p}$ : depth of cut inside material (figure 3). The equation Eq. 5 is used to carry out to determinate the points $P_{C C i \_d e f \_d e c}(x i, y i, z i)$.

$$
O P C C i \_d e f \_d e c(x i, y i, z i)=O P^{\prime} C C(x i, y i, z i)+(E i-a p) . n
$$

It will be noted that, on a meshed surface (plane element); the local normal is submitted at discontinuous variations along a toolpath. This last will induce discontinuities on the deformed toolpath [3]. This deformation induces oscillations, principally, in the axis of the machine and this is observed in the manufacturing surface, because the initial trajectory is far from the target surface (figure 4). To resolve this impediment, section 5 proposes a method to smooth the toolpath within a pre-assigned tolerance.
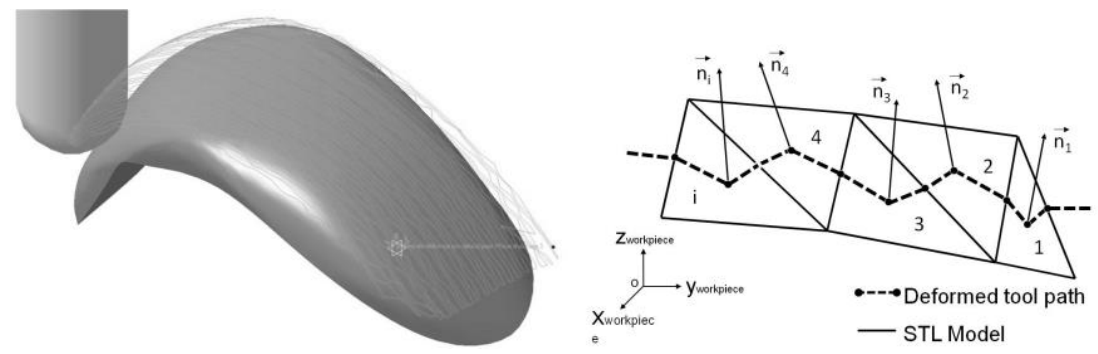

Figure 4: Discontinuities observed on the deformed tool path.

The generation of toolpath starting from model STL generates disturbances of deformed trajectory then decelerations of the machine and defects on the part. These phenomena are harmful with respect to production and the surface quality. 
Toolpath smoothing is carried out to improve surface quality after the deformation step. A technique of smoothing methods is developed in literature. Some authors propose the B-Spline curve interpolation to smooth the nominal toolpath points [8-9].

\section{Smoothing toolpath and experimental validations}

The proposed smoothing method is based on smoothing axis by axis with a 3dimensional admissible tolerance IT. This method may be applied to the 3 axes of the toolpath or only to one. On each axis a low degree polynomial $(<6)$ is calculated using the least squares method. In addition with that, we propose to use the Bezier curves to smooth the toolpaths with an aim to have a better surface quality.

Tests are carried out on a femoral prosthesis. This prosthesis is a unicompartmental knee component. Shape complexity of these surfaces requires machining by a multi-axis CNC machine, in this case five-axis "ULTRASONIC 20 linear". A Siemens 840D CNC was used to carry out the tests. The measurement of manufacturing time gives us an idea of the effectiveness of the smoothing technique and makes it possible to select the most smooth toolpath trajectory as shown in the figure 5. It shows clearly that the proposed technique of smoothing by Bezier curves offers a better fluidity.
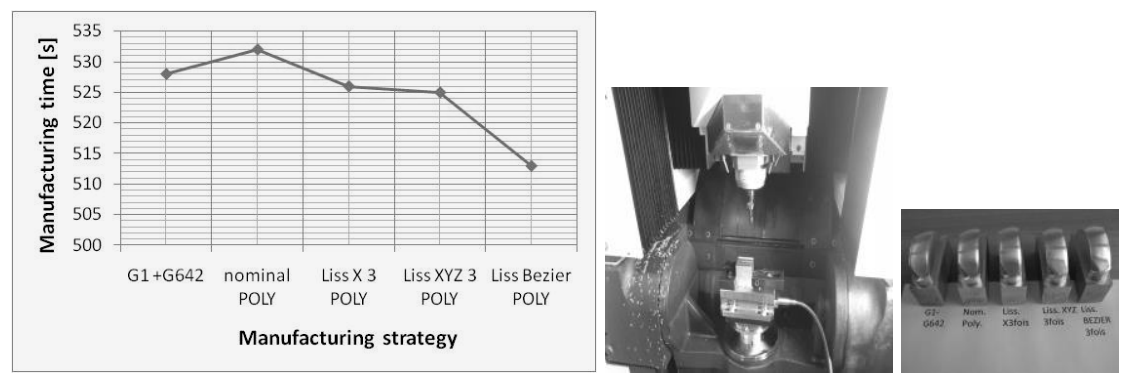

Figure 5: Experimental testing and validation.

The machined surfaces are measured with an optical coordinate measuring machine. Figure 6 presents the obtained results. This figure illustrates the roughness surface to the machined surface and compares the total depth of surface in micron $[\mu \mathrm{m}]$. 


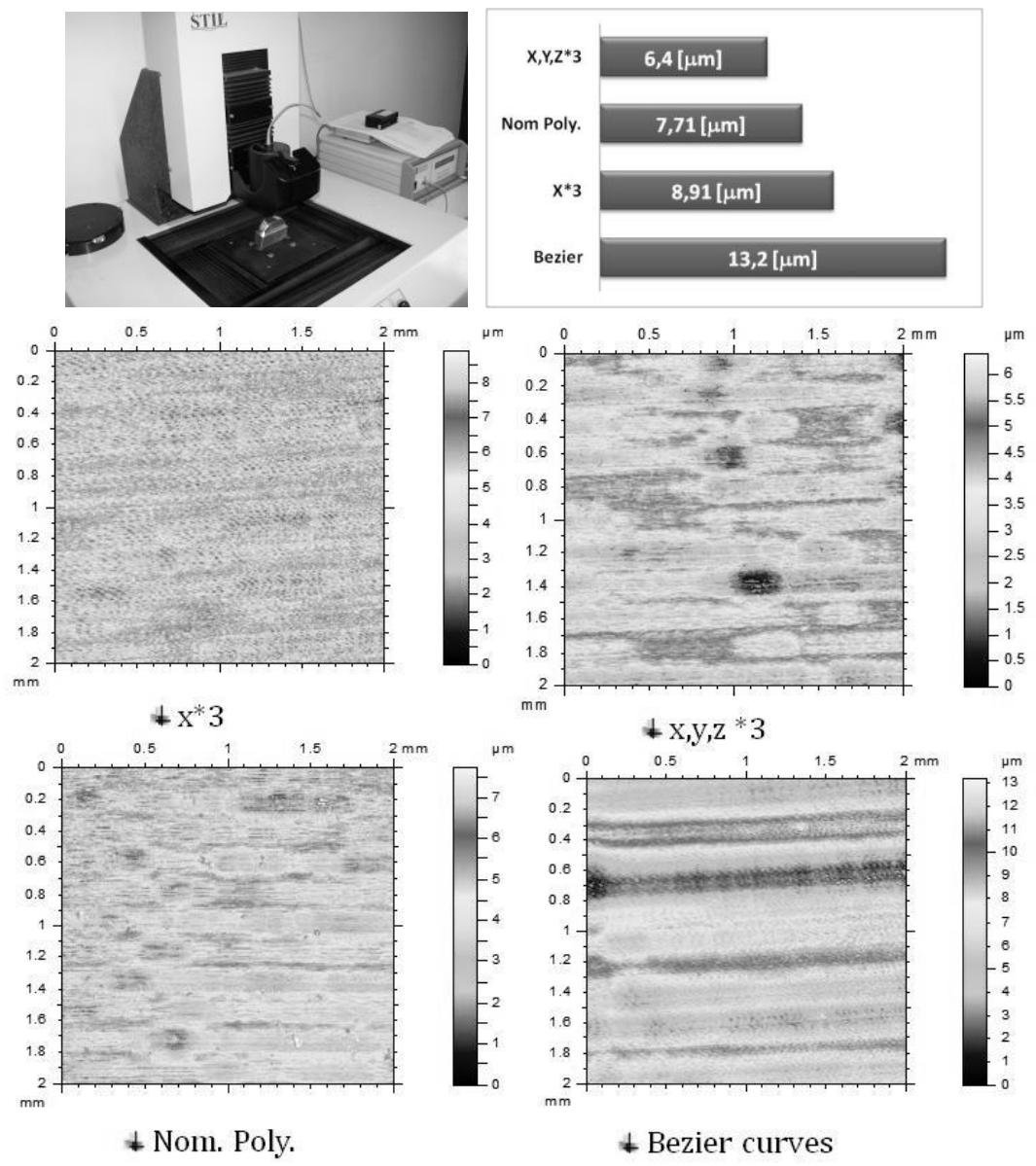

Figure 6: The measurement roughness surface results.

From the machining experiments and the results of roughness measurements, we can conclude that the best strategy is the smoothing according to the three machine axes $\mathrm{X}, \mathrm{Y}, \mathrm{Z}$.

\section{Conclusion}

In this paper a method to adapt a toolpath to a geometrical target to remove a constant thickness on a rough surface was proposed. This case is generally present in the production of knee prostheses. An STL model is generated after the measurement process. The toolpath deformation method starts with aligning the measured surface and the nominal toolpath. After this, a deformation 
toolpath method is proposed to remove a constant thickness on rough surface. However, the use of a meshed model to deform the toolpath induces systematic effect (apparition of pattern marks) on the manufactured surface. To resolve this problem, a toolpath smoothing methods was developed. To validate the usefulness of the presented method and its effects on the machined surface quality, industrial tests were carried out and analyses, leading to an optimal method based.

\section{References}

1. Gacon G, Hummer J (2006). Les prothèses tricompartimentaires du genou de première intention. Techniques opératoires. Problèmes et solutions. Collection GECO. Springer-Verlag France, Paris.

2. Lison D, Lauwerys R, Demedts M, Nemery B. (1996), Experimental research into the pathogenesis of cobalt/hard metal lung disease, European Respiratory Journal 9: 1024-1028. doi: 10.1183/09031936.96.09051024

3. Azzam N., Chaves-Jacob J. Boukebbab S, Linares J.M. (2014), Adaptation of machining toolpath to distorted geometries: application to remove a constant thickness on rough casting prosthesis, International Journal of Advanced Manufacturing Technology. DOI 10.1007/s00170-014-5738-2

4. Hu Gong, Li-Xin Cao, Jian Liu (2005), Improved positioning of cylindrical cutter for flank milling ruled surfaces, Computer-Aided Design 37 12051213.

5. Chaves-Jacob J, Linares J-M, Sprauel J-M (2013), Improving tool wear and surface covering in polishing via toolpath optimization, Journal Of Materials Processing Technology 213/10: 1661-1668. Doi: 10.1016/j.jmatprotec.2013.04.005

6. S. Rusinkiewicz and M. Levoy, Efficient Variants of the ICP algorithm, in Proceeding of the 3rd IEEE International Conference on 3-D Digital Imaging and Modeling, Quebec, 2001, pp. 145-152

7. Boukebbab S, Bouchenitfa H, Boughouas H, Linares JM (2007), Applied Iterative Closest Point algorithm to automated inspection of gear box tooth, International Journal of Computers \& Industrial Engineering 52: 162-173. doi: $10.1016 /$ j.cie.2006.12.001.

8. Can A, Ünüvar A. (2010), Five-axis tool path generation for 3D curves created by projection on B-spline surfaces, International Journal of Advanced Manufacturing Technology. Vol. 49. pp 1047-1057.

9. Pechard P-Y, Tournier C, Lartigue C. Lugarini J-P. (2009), Geometrical deviations versus smoothness in 5-axes high-speed flank milling, International Journal of Machine Tools \& Manufacture. Vol. 49. pp 454461. 